\title{
POWER FACTOR CORRECTION(PFC) PREREGULATOR USING BOOST CONVERTER FOR 2 kVA POWER SUPPLY
}

\author{
Rahul Chavhan, Dr.Champa \\ Department of Electricals and Electronics Engineering \\ B.M.S College of Engineering, Bengaluru, Karnataka, India
}

\begin{abstract}
Many of the power electronics applications involves AC-DC conversion stage followed by SMPS to regulate output. Power factor plays an important role in Active Power transfer; Power electronic switching devices such as SMPS, uninterruptible power supply (UPS), inverters, rectifier induces high distorted input current for small period because of their nonlinear nature. It leads to magnetic interference with other circuits, high Total Harmonic Distortion (THD) and low power factor (PF). This issue can be addressed by using a boost converter as an active power factor correction pre-regulator. Input voltage is varied from $90 \mathrm{~V}-265 \mathrm{~V}$ and output voltage is $390 \mathrm{~V}$. At low voltage $(90 \mathrm{~V})$ conduction losses are high and efficiency is low, so input varied from $170 \mathrm{~V}$ to 265V. In this work MATLAB/Simulink Simulation of Boost PFC along with a PI controller is presented. 2000W Boost PFC operating in Continuous Conduction Mode (CCM) is implemented using controller Texas UCC28180 IC (Integrated Circuit). Power factor, THD, Efficiency analysis is done at different load conditions and results are encouraging.
\end{abstract}

Key words - Switch Mode Power Supply, Power Factor, Total Harmonic Distortion, Power Factor Correction, Continuous Conduction Mode, Boost Converter, Average Current Mode Control, PI Controller.

\section{INTRODUCTION}

Power supplies are used in most of applications such as space and telecommunication power supplies, AC adapter, battery charger, Dc motor drives, and other home applications. These applications use a Power Factor Correction (PFC) step to increase input power factor and decrease voltage regulation and Total Harmonic Distortion (THD) of input current. Without PFC and filters, current has harmonic content due to discontinuous currents drawn over a small duration leading to rise in network losses, radiated emission and THD [2]. At higher power stages these problems becomes more prominent, thus decreasing efficiency of the system.

"Power factor is the ratio between the Real Power and Apparent Power in ac circuit" [11]. Real Power denotes net energy transferred to load over one complete cycle. While reactive power denote the fraction of power that temporarily stored by the load. Apparent power represents vector addition of real and reactive power, but in case of nonsinusoidal periodical signals more complex relations considered.

$\mathrm{PF}=($ Real power $) /($ Apparent Power $)$

When this ratio deviates from unity leads to phase displacement and degradation of power factor. "Reactive power in the system is due to two reasons, Phase shift of current with respect to voltage, resulting in displacement harmonic and distortion" $[2,6]$. Displacement Factor and Distortion Factor gives the power factor given as Power Factor $=$ Displacement Factor $\mathrm{x}$ Distortion Factor

Power Factor $=\frac{\cos \theta}{\sqrt{1^{2}+T H D^{2}}}$

Where: $\cos \theta$ is Displacement Power Factor (DPF) and $\theta$ is phase angle between the fundamental voltage and current. "Displacement Power factor is the power factor due to phase shift between voltage and current at fundamental line frequency" [11]. It is clear from the earlier Equation (1) that we can obtain high power factor when harmonics content is low. "THD is quadratic sum of the unwanted harmonics over the fundamental that gives the relative weight of the harmonic content with reference to the fundamental" [6].

PFC circuits used in SMPS to maintain inphase relation between input voltage and current, reduce current distortion and increase efficiency of system. Active PFC and passive 
PFC are the techniques available for power factor correction. Passive PFC is simple and inexpensive technique where tuning of passive elements done to reduce higher order harmonics. But it has some disadvantages like aging of passive element and it requires large space. Power electronic switches used in combination with passive elements to control current and voltage. Control over current and voltage obtained by turning on and off at instant of control required to obtain unity power factor. Active PFC implemented by average current mode control or peak current mode control [5]. Realization of Active PFC can be done through DC-DC conversion topologies such as buck, boost and buck- boost used in active power factor correction $[5,6]$.

\section{ACTIVE PFC AND ADVANTAGES}

Active power factor correction can be realized through different techniques of DC-Dc conversion. Boost converter has characteristics of boosting the output voltage to required voltage, switch is placed at low voltage side hence "current sense and gate drive control is easy, inductor is on source side which regulate source current and eliminates the external use of inductor thus space and cost reduced"[2]. Because of these advantages Boost converter is used in most of the applications.

"Boost converter switch can be operated in Discontinuous Conduction Mode (DCM), Continuous Conduction Mode (CCM) And Critical Conduction Mode (CrCM) depending on current through boost inductor within a switching cycle" [6]. In CrCM the switch has to turn-on at exactly zero crossing of inductor current hence sensing of inductor current should be fast and accurate. $\mathrm{CrCM}$ is more suitable for low power applications because it has more peak current through the energy transfer inductor and variation of frequency depends on load condition. It involves more copper losses and core losses. These drawbacks can be overwhelmed by controlling switch in CCM [1, 6]. Losses can be reduced with use of fast reverse recovery diode.

\section{BLOCK DIAGRAM OF BASIC PFC}

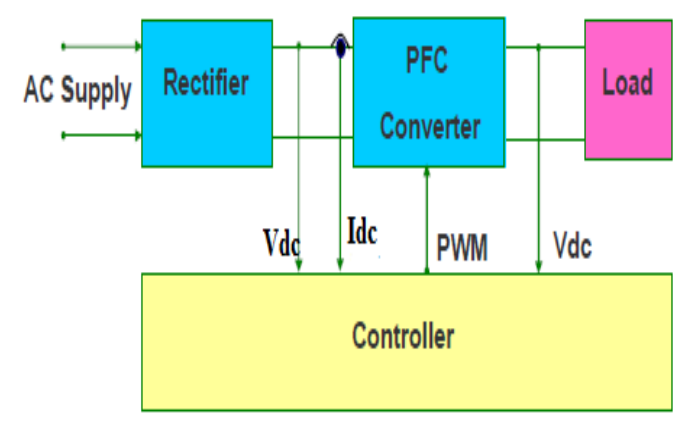

Figure 1: Block diagram of basic power factor control

The Figure 1 shows the basic block diagram of the converter with active Power Factor Correction. It consists following elements.

\section{i. Rectifier}

It converts alternating current $(\mathrm{AC})$ into direct current (DC) using diodes in bridge configuration. It typically includes of four number of diodes which causes the output to be generated of same polarity regardless of polarity of input. Capacitor is connected across the output of bridge rectifier to reduce ripple in voltage.

\section{ii. Boost Converter}

Boost converter comprise of Boost Inductor (L), MOSFET (M), Diode (D) and Capacitor (C) as shown in below figure $2 \mathrm{a}$. Switch (M) can be controlled by Pulse Modulation Technique with constant switching frequency but variable duty cycle. During on period of switch Diode (D) is reverse biased and voltage across inductor is $V_{d c}$, current in inductor rise with slope $\frac{V_{d c}}{L}$ and inductor stores energy during this period [1]. During (1D)Ts switch is off, Diode is forward biased and Voltage across inductor $V_{d c^{-}} V_{o}$ and inductor current decreasing with slope $\frac{V_{d c}-V_{o}}{L}$ and inductor delivers energy to load during this period. From volt-sec balance equation inductor average voltage is zero over cycle [7]. Output equation of boost converter given as

$$
V_{o}=\frac{V_{d c}}{(1-\mathrm{D})}
$$




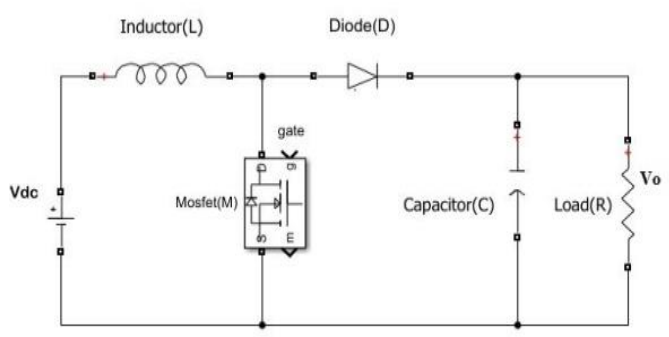

a)

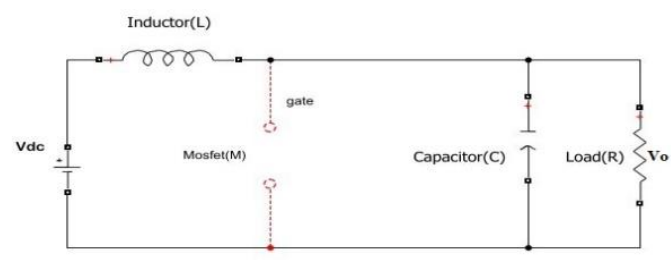

b)

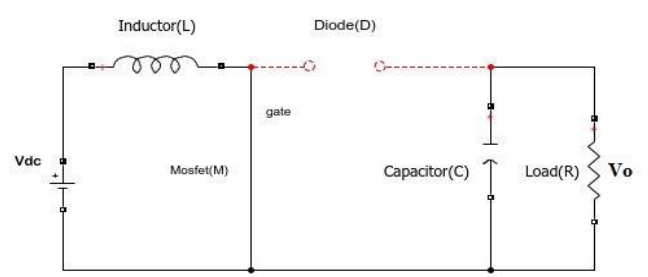

c)

Figure 2: a) Circuit diagram of boost converter b) Circuit during switch on c) Circuit during switch off

\section{iii. Controller Strategy}

Control scheme can be realized by using voltage mode control and current mode control. In PFC, current mode based controller is implemented. Current signals have natural

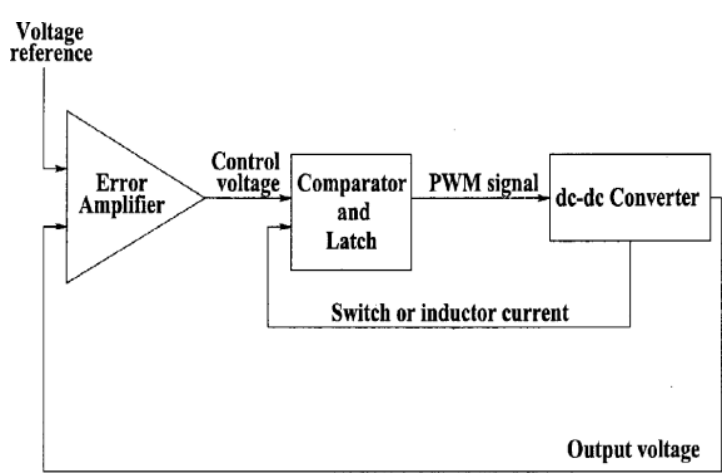

advantage over voltage signals in control scheme.
Figure 3: Schematic diagram for current mode control

In voltage control scheme, output of DCDC converter is compared with voltage reference. Output of error amplifier between the signals taken as control voltage. Control voltage is compared is compared with constant amplitude sawtooth signal. Comparator or PWM modulator produces PWM signal, these signals control duty cycle of switch. Duty cycle depends on control voltage and frequency is same as sawtooth waveform.

Current control scheme is shown in fig.3. It consists of additional inner current loop compared to voltage control. Here both current and voltage control is possible. Scheme developed in such a way that input current tracks line voltage. Multiplication of line voltage and output of error amplifier gives current reference signal, this makes current reference signal to follow line voltage. Reference current compared to inductor current in PWM comparator, resulting pulses drives switch. Main difference between these two schemes is way of reference signal generation.

Peak Current Control (PCC), Average Current Mode Control (ACMC) is used in implementation of current control. Peak current mode control not suitable for duty cycle more than 0.5 due to stability problems. Thus ACMC is used increase power factor using boost converter shown in fig. 4 [5]. ACMC has some benefits like peak inductor current value is restricted, good noise immunity, effective control and less error difference between peak to average current. In ACMC the error between output voltage and reference voltage is amplified and multiplied with line voltage. Output of multiplier compared with boost inductor current and output given to MOSFET driver.

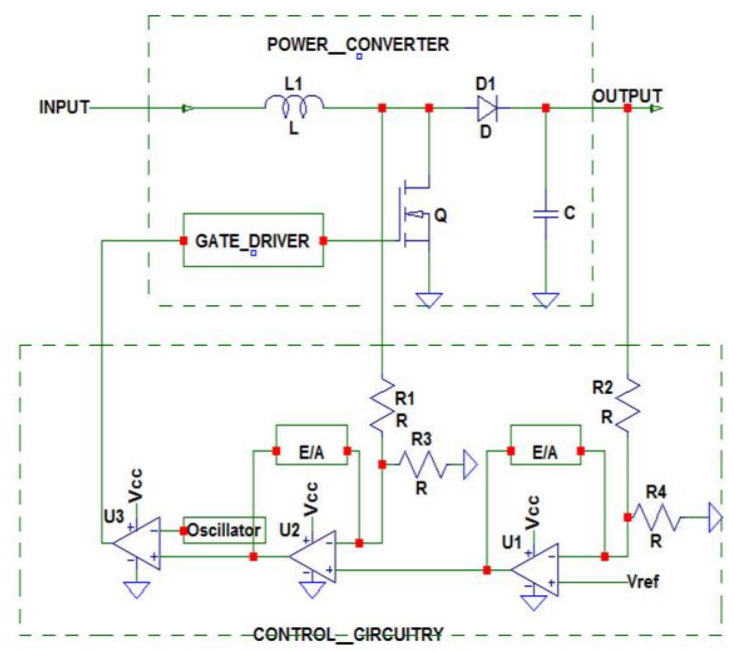

Figure 4: PFC control circuit 


\section{International Journal of Engineering Applied Sciences and Technology, 2020 \\ Vol. 5, Issue 3, ISSN No. 2455-2143, Pages 439-445 \\ Published Online July 2020 in IJEAST (http://www.ijeast.com)}

The controller used in hardware is "UCC28180D is a variable frequency CCM Boost power factor controller. The frequency is fixed by connecting suitable resistor across frequency pin. Special features of controller are good dynamic response, over voltage and under voltage protection with hysteresis recovery"[8]. "Current sense has two functions i.e to limit peak current through the boost inductor and to control the duty cycle of switch by sensing the input current. Current sense resistor of very low value is used; the current is proportional to voltage across the resistor" [8].

\section{DESIGN METHODOLOGY}

The specifications of circuit as follows;

AC Input Voltage: $(170-265) \mathrm{V}$

Input Frequency: $50 \mathrm{~Hz}$

Switching Frequency: $45 \mathrm{kHz}$

Output: 400V/5.12A

Allowed Ripple in Output Voltage: $2 \%$

Efficiency: $\leq 98 \%$

Consider maximum efficacy of $98 \%$. Maximum load current for $2000 \mathrm{~W}$ power and $390 \mathrm{~V}$ constant output voltage

Io $=\frac{P o}{V o}=\frac{2000}{390}=5.128 \mathrm{~A}$

When converter is operating at minimum Vin of $170 \mathrm{~V}$, Imax will be drawn from the source i.e max input RMS line current is

I_linemax $=\frac{P o}{n * V_{-} \min }=\frac{2000}{0.98 * 170}=12 \mathrm{~A}$

The peak input current is given by

I_ peak $=\sqrt{2} *$ I_linemax $=\sqrt{2} * 12=17 \mathrm{~A}$

The maximum average rectified line current

I_in_avg_max $=\frac{2 * \sqrt{2}}{\pi} *$ I_linemax $=10.8 \mathrm{~A}$

Bridge rectifier has a forward voltage drop of 0.95 $\mathrm{V}$ and power loss calculated as

P_br_ $\max =2 * 0.95 *$ I_in_avg_max $=$ $2 * 0.95 * 10.8=20.5=21 \mathrm{~W}$

The bridge rectifier rated to carry the full line current. The voltage rating of the bridge should be more than $600 \mathrm{~V}$. The bridge rectifier carries the full inrush current which charges capacitor connected in line.

Selecting Switching Frequency

The UCC28180 switching Frequency is user programmable with single resistor on FREQ pin to GND [8].

Design uses $45 \mathrm{kHz}$ frequency

$R_{F R E Q}=\frac{R_{T Y P *} R_{I N T *} F_{T Y P}}{\left(f_{S W} * R_{I N T}\right)+\left(R_{T Y P *} f_{S W}\right)-\left(R_{T Y P *} f_{T Y P}\right)}$

Where $R_{T Y P}, R_{I N T} f_{T Y P}$ constants are internally fixed to controller based on UCC28180 controller logic

$R_{T Y P}=32.7 \mathrm{k} \Omega$

$R_{I N T}=1 \mathrm{M} \Omega$

$f_{T Y P}=65 \mathrm{kHz}$

$R_{F R E Q}=\frac{65 \mathrm{kHz} * 32.7 \mathrm{kohm} * 1 \mathrm{Mohm}}{(45 \mathrm{kHz} * 1 \mathrm{Mohm})+(32.7 \mathrm{k} * 45 \mathrm{k})-(65 \mathrm{k} * 32.7 \mathrm{k})}=$ $47.9 \mathrm{k} \Omega$

A typical value of $47 \mathrm{k} \Omega$ for FREQ resistor results in switching frequency of $44 \mathrm{kHz}$

Output of bridge rectifier contains ripple of $\mathrm{Vm}$ peak to peak, reduction of ripple done by placing a capacitor across it.

$C_{\text {bridge }}=\frac{I_{\_} \text {ripple }}{8 * F_{\text {SW }} * V_{\text {in_ripple }}}$

Where, $I_{\text {ripple }}=\Delta I_{\text {ripple }}{ }^{*} I_{\text {maxin }}$, approximate input ripple current through inductor 20 to $35 \%$, more the percentage of ripple current less the value of inductance and may results in DCM mode of operation in light load condition. For enriched operation 35\% ripple chosen.

To regulate the output voltage pulse width should be varied. At maximum input voltage (Vin_max) minimum duty (Dmin) cycle and minimum input voltage (Vin_min) maximum duty cycle(Dmax), expression for duty cycle given by

$\frac{V o}{V_{-} \text {in }}=\frac{1}{1-D}$ i.e $D_{\text {max }}=1-\frac{V \_ \text {in_min }}{V_{-} \text {out }}$

$D_{\max }=1-\frac{170}{390}$

$D_{\max }=0.564$ we are taking $D_{\max } 0.8$

$D_{\text {min }}=1-\frac{265}{390}=0.320$

The selection of the boost inductor different parameters considered like Cost, core size, EMI filter, and inductor ripple current etc. Inductor ripple current of $40 \%$, PFC choke inductor is 
designed after calculating the maximum inductor peak current $I_{P K}$

$I_{P K}=\frac{\sqrt{2} P_{0}}{\text { Efficiency } * V_{I N \_M I N}}=\frac{\sqrt{2} * 2000}{098 * 170}=17$ Amps

Inductor minimum value calculated based on acceptance of ripple current $I_{\text {ripple }}$

$$
\begin{aligned}
& L_{M I N} \geq \frac{\sqrt{2} * V_{I N_{M I N}} * D_{M I N}}{I_{P K^{*}} * 0.4 * f_{S W}}=\frac{\sqrt{2} * 170 * 0.31}{17 * 0.4 * 45 e 3}=591.5 \mu \mathrm{H} \\
& L_{M A X} \geq \frac{\sqrt{2} * V_{I N_{M I N}} * D_{M A X}}{I_{P K^{*}} * 0.4 * f_{S W}}=\frac{\sqrt{2} * 170 * 0.8}{17 * 0.4 * 45 e 3}=628 \mu \mathrm{H}
\end{aligned}
$$

Schottky Power diode is chosen because "the forward voltage drop and reverse recovery charge of the diode should be low to improve the efficiency of converter. Output converter maintain the holdup time of converter and supply load current during switch on"[8].

Output voltage is sampled using sampling resistors in such way that if Vout reaches $400 \mathrm{~V}, 5 \mathrm{~V}$ will appears across R14 resistor. "Sensed output voltage is compared with reference and error between these voltages amplified and compared with voltage across current sense resistor to vary the switching period"'[8].

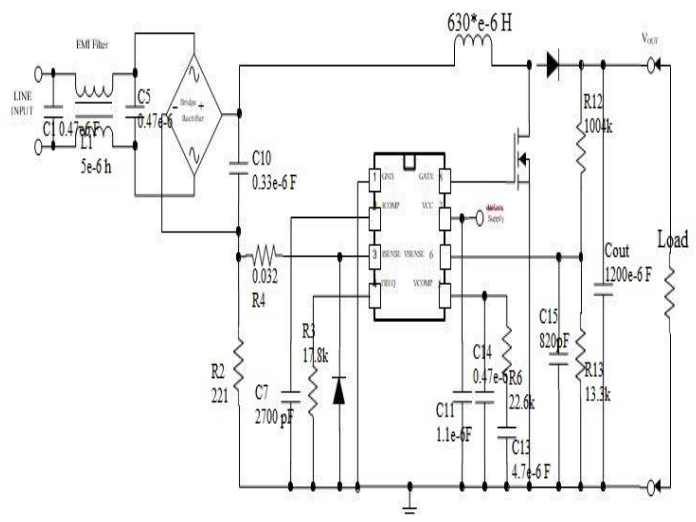

Figure 5: Design schematic for PFC using Boost Converter

Table 1 : PFC component values

\begin{tabular}{|l|c|l|}
\hline Sr. No & Parameter & Value \\
\hline 1 & $L_{\text {boost_min }}$ & $592 \mu \mathrm{H}$ \\
\hline 2 & $D_{\max }$ & 0.8 \\
\hline 3 & $C_{\text {out }}$ & $1200 \mu F$ \\
\hline
\end{tabular}

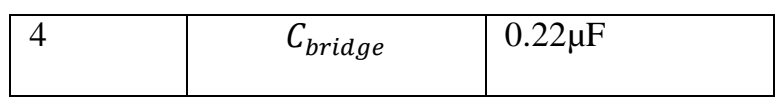

\section{SIMULATION AND RESULT DISCUSSION}

a) Circuit Diagram

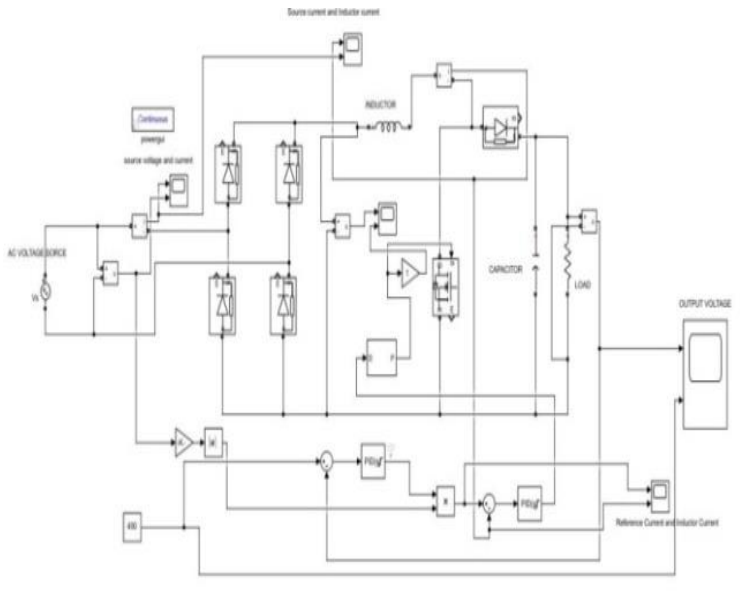

Figure 6: Simulation of PFC using MATLAB Simulink

Simulation of power factor correction using boost converter by MATLAB Simulink tool as shown in above fig 6 . In this circuit output voltage is compared with reference voltage and error is given to PI controller which minimizes error between these voltages i.e steady state error is reduced. Source voltage is sensed and unity amplitude obtained using mod block because source voltage is taken as reference which generates current reference. Out of PI controller is constant value multiplied with unity amplitude voltage to generate current reference. Current reference compared with inductor current and error is given to PI controller. According error pulses are generated and switching is controlled. Reference current forces inductor current to be half sinusoidal, if inductor current is half sinusoidal then source current will be sinusoidal which indicates source voltage and current are in phase. Source current and voltage is in phase indicating nearly unity power factor.

b) Simulation Results

From simulation, before power factor correction it is observed that source voltage and current are not in phase, current is in distorted form which indicates high THD shown fig 7. 


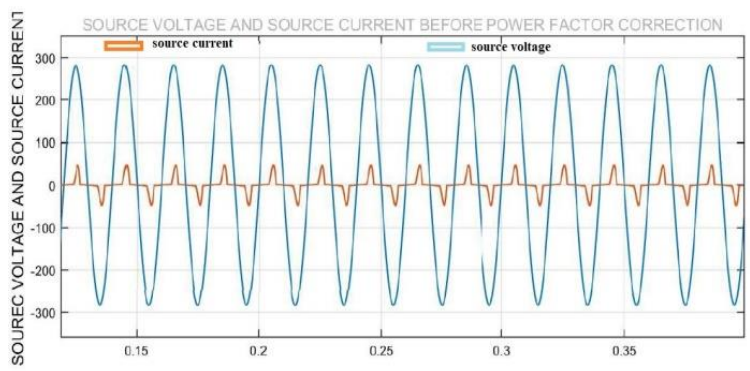

Figure 7: Source voltage and Current Waveforms before PFC

From FFT analysis we observe that THD is high shown in fig 8 .

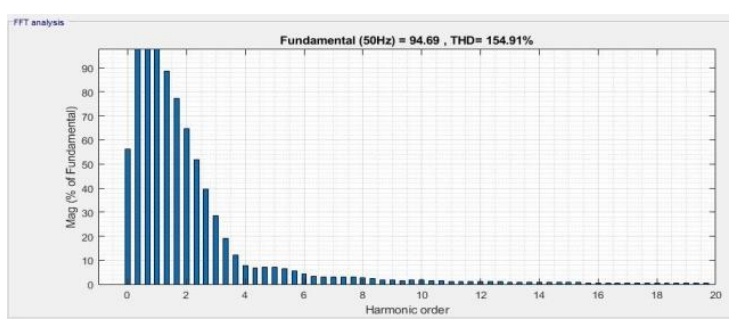

Figure 8 : THD before Power Factor Correction

We can observe out voltage of $400 \mathrm{~V}$ from Boost Converter input $170 \mathrm{~V}$ having duty ratio of 0.567 shown in fig 8 .

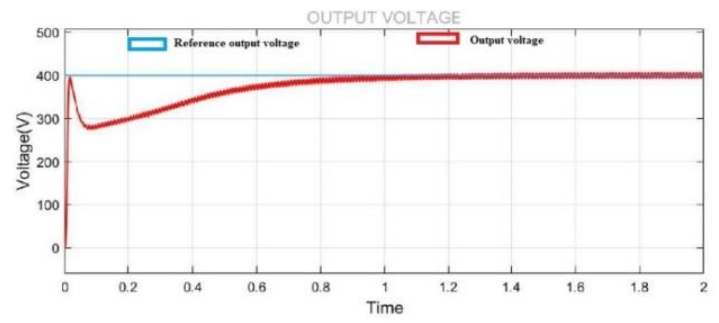

Figure 9: Output Voltage

With change in output voltage reference, circuit output also changes shown in fig 9 because reference output voltage is multiplied with phase of input voltage and results compared with inductor current error given to PI controller generates duty cycle according to change in reference.

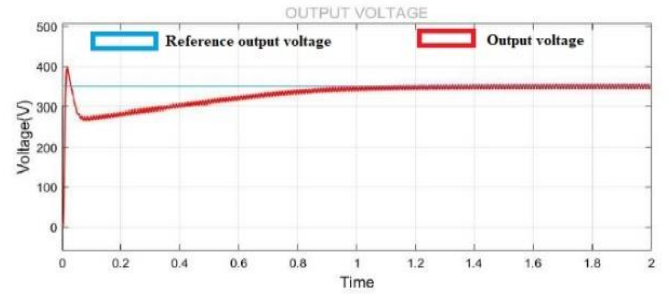

Figure 10: Output voltage when step or reference voltage set to $350 \mathrm{~V}$
From fig 10, source voltage and source current are in phase that indicates nearly unity power factor

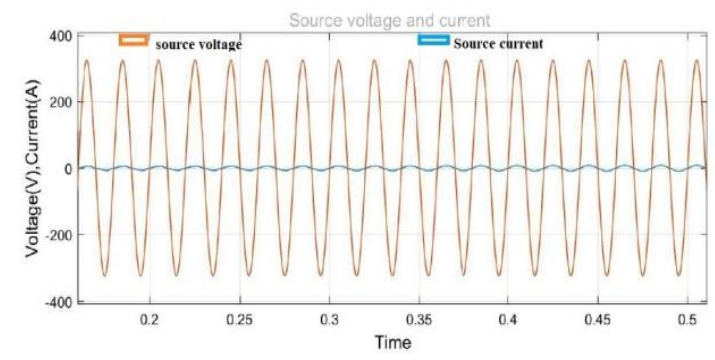

Figure 11 : Source voltage and Source current waveform

After power factor power factor is nearly unity and THD is reduced observed from simulation shown in fig 12.

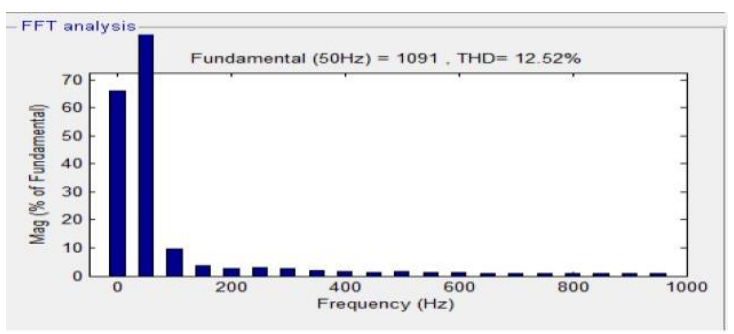

Figure 12: THD after power factor correction

To generate required output with change in load reference current must track inductor current shown in fig 11 .

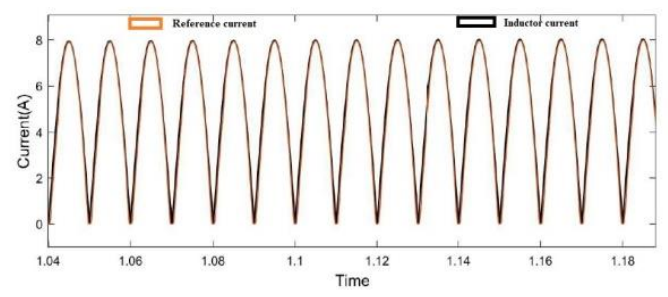

Figure 13: Inductor and reference current

From fig 12 it is observed that inductor current is continuous and source current sinusoidal of same magnitude as inductor current.

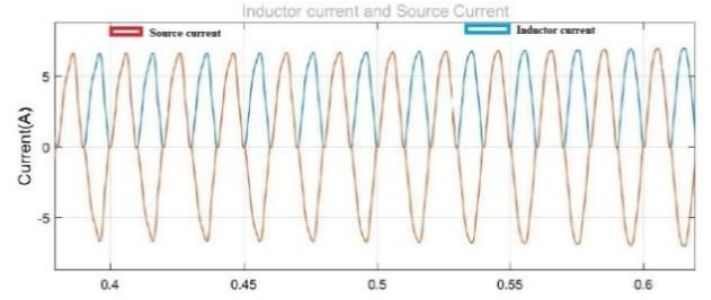

Figure 14: Source Current and Inductor Current 


\section{International Journal of Engineering Applied Sciences and Technology, 2020 \\ Vol. 5, Issue 3, ISSN No. 2455-2143, Pages 439-445 \\ Published Online July 2020 in IJEAST (http://www.ijeast.com)}

c) Hardware Implementation

Experimental setup of Active PFC using boost converter is developed for $2000 \mathrm{~W}$. It consist components like inductor $(630 * \mathrm{e}-6 \mathrm{H}$ Toroidal core), MOSFET (N- channel $600 \mathrm{~V}, 39.9 \mathrm{~A}$, part no- IPW60R099P6), PFC Diode (600 V, 3 A, part no-IN5406), Output Capacitor (1200e-6 F), Fuse (Cartridge 250V, 30 A), Positive Temperature Coefficient Thermistor (PTC 47 ohm part noB470), Bridge Rectifier (800 V, 35 Amp part no GBJ3508). Power circuit is tested with different load, voltage and current to observe input power and output power to calculate the efficiency. Power factor and THD observed using harmonic analyser.

The results PFC circuit at $50 \mathrm{~Hz}$ shown below

Table 2 : Results of PFC Circuit at $50 \mathrm{~Hz}$

\begin{tabular}{|l|l|l|l|l|l|}
\hline $\begin{array}{l}\mathrm{f} \\
\text { in Hz }\end{array}$ & $\begin{array}{l}\text { Vin } \\
\text { volts }\end{array}$ & Iin & Pin & $\begin{array}{l}\text { Power } \\
\text { factor }\end{array}$ & $\begin{array}{l}\text { Efficiency } \\
\%\end{array}$ \\
\hline $50 \mathrm{~Hz}$ & 170 & 13.2 & 2154 & 0.94 & 93 \\
\hline $50 \mathrm{~Hz}$ & 200 & 11.2 & 2128 & 0.95 & 94 \\
\hline $50 \mathrm{~Hz}$ & 230 & 9.5 & 2075 & 0.95 & 96 \\
\hline
\end{tabular}

Where f- Frequecy, Iin - input current, Vin- Input voltage, Pin- Input power

Comparison of Results show in Table 3;

Table 3 : Comparison of Result

\begin{tabular}{|l|l|l|l|l|}
\hline Voltage & $\begin{array}{l}\text { Before } \\
\text { PFC } \\
\text { PF }\end{array}$ & $\begin{array}{l}\text { Before } \\
\text { PFC } \\
\text { THD \% }\end{array}$ & $\begin{array}{l}\text { After } \\
\text { PFC } \\
\text { PF }\end{array}$ & $\begin{array}{l}\text { After } \\
\text { PFC } \\
\text { THD \% }\end{array}$ \\
\hline 200 & 0.65 & 154 & 0.95 & 17 \\
\hline 230 & 0.6 & 150 & 0.94 & 18 \\
\hline
\end{tabular}

\section{CONCLUSION}

Active power factor correction (PFC) using boost converter operating in CCM mode is simulated along with a PI controller using Matlab/Simulink. Simulation model provides power factor of 0.99 and THD of $13 \%$ and hardware results of power factor and THD are 0.95 and $18 \%$. Thus implementation resulting in power factor improvement and THD reduction in SMPS. PFC controller has shown encouraging results with power factor more than 0.9 and THD between 6$20 \%$ thus improving power quality.

\section{REFERENCES}

[1] Active PFC for power electronics supplies, Application Note VICOR.

[2] Rashid M., Power Electronics Handbook.

[3] Sukanta Kumar Sahoo Department of Electrical Engineering,S. V. National Institute of Technology, Surat, Gujarat "A New Power Factor Correction Technique Using PFC Boost Converter",2012 11 th International conference on Environmental and Electrical Engineering(EEEIC).

[4] Sujata Powniker,Student Member, IEEE and Sachin Shelar, Member "Development of Active Power Factor Correction Controller Using Boost Converter", IEEE AISSMS's IOIT, Pune, India. 2016

[5] Kotari Sri Harsha Babu, Ramesh Holde Centum Electronics Ltd, Bangalore "Power Factor Correction using Boost Converter Operating in CCM for Front-End AC to DC Conversion", India 2018 IEEE International Conference on Technologies for Smart-City Energy Security and Power (ICSESP-2018), March 28-30, 2018, Bhubaneswar, India

[6] On semiconductor power factor correction Handbook.

[7] Daniel Hart, "Power Electronics", McGraw Hill, 2011.

[8] Data sheet UCC28180D- Texas Instruments Controller for power factor correction.

[9] Integrating the current sense resistor by Scott Hill, from Current sensing products by Texas Instruments.

[10] TIDA-00779 230-V,3.5-kW PFC with $>98 \%$ Efficiency, Optimized for BOM and size reference Design

[11] N. Mohan, T.M.Undeland, and W.P. Robbins, Power Electronics; Converter, Applications and Design, $3^{\text {rd }}$ edition New York,USA:Willy, 1989.

[12] Average Current Mode Control of Switching power supplies by Loyd Dixon a Unitrode application note. 